\title{
Seismic Safety Assessment of Existing Low-rise RC Buildings with Rapid Visual Screenings and Preliminary Evaluation Methods
}

\author{
Moe Myat Myat Aung ${ }^{1, *}$ and Mya Nan Aye ${ }^{1}$ \\ ${ }^{1}$ Civil Engineering Department, Mandalay Technological University, Shin Taw Gone Village, Patheingyi Township, Mandalay, Myanmar \\ ${ }^{*}$ Corresponding author: moe040604@gmail.com
}

\author{
KEYWORDS \\ Low-rise building \\ Rapid visual screening \\ Preliminary evaluation \\ Seismic safety assessment \\ SUBMITTED 6 October 2020 \\ REVISED 8 April 2021 \\ ACCEPTED 15 April 2021
}

\begin{abstract}
Mandalay, the second largest city in Myanmar, is situated near the Sagaing Fault (the major fault in Myanmar). In the Mandalay region, the number of low-rise buildings is much greater than that of high-rise buildings. As such, seismic safety assessments of low-rise buildings play an important role in developing Mandalay as a smart city. In this study, the rapid visual screening (RVS) and preliminary evaluation for 26 numbers of three- to eight-story RC buildings were investigated with three different RVS and preliminary evaluation methods. Based on the RVS methods, the FEMA P154 Level 1 and 2 results gave the highest risk. With the Bangladesh method, the higher the story, the more vulnerable the building. Meanwhile, the Indian method showed a medium risk status. According to the preliminary evaluation, the assessed buildings need a detailed seismic evaluation, except for one building in the Indian method. Similarly, all buildings need a detailed evaluation in the Bangladesh method. The most convenient RVS and preliminary evaluation can be derived from these results for buildings in Mandalay, Myanmar. Moreover, a method can be developed for seismic safety assessments in other ASEAN countries with subsequent research.
\end{abstract}

(c) The Author(s) 2021. This article is distributed under a Creative Commons Attribution-ShareAlike 4.0 International license.

\section{INTRODUCTION}

Earthquakes are random in nature and unpredictable. Therefore, analysis of the structures under the action of earthquakes requires better engineering approaches and tools to economically design the structures. Mandalay is in the a seismic zone and $0.2 \mathrm{~s}\left(\mathrm{~S}_{2}\right)$ and $1.0 \mathrm{~s}\left(\mathrm{~S}_{1}\right)$ spectral response accelerations are 2.01 and 0.8 (UN-Habitat 2016). In the Seismic Zoning Map of Myanmar for Alternative Seismic Design Procedure, according to Chapter 16 of the UBC97 Code, Mandalay belongs to seismic zone V (0.4-0.5g) and has an equivalent modified Mercalli Scale class IX.

Most of the low-rise buildings in Mandalay are more vulnerable to seismic load than high-rise buildings because seismic design regulations for low-rise buildings in Myanmar were been defined until 2019. Thus, seismic safety assessments for existing low-rise buildings in Mandalay need to be carried out.

The seismic vulnerability assessment methods constitute three stages: rapid, preliminary, and detailed assessments. Rapid visual screening (RVS) is the basic key to measuring the seismic capacity of buildings. It is carried out with rapid visual assessments and street surveys. Preliminary evaluation is the second step of the seismic vulnerability assessment, and some simple calculations are carried out with more accurate input data. Detailed seismic evaluations are very important for seismic safety assessments of buildings. This procedure needs a lot of time, cost, much effort, a complex technical background, and procedure.

Rapid assessment and preliminary assessment procedures have been developed to handle large building stocks for ranking and prioritizing their seismic risk (Yakut 2014). These two steps can provide support data for the detailed seismic evaluation and strengthening of seismically vulnerable buildings.

In previous studies featuring RVS by Win and Zaw (2018) and Aye and Aye (2019), the RVS of buildings in Myanmar was carried out with the FEMA standard because this is the most common RVS method. Therefore, FEMA is used to assess the seismic safety of the low-rise buildings in the present study. India and Bangladesh, which are developing ASEAN countries, also developed their own methods to determine seismic safety. These methods may be more compatible with Myanmar. And hence, FEMA P-154, the Indian method, and the Bangladesh method are used for the RVS of buildings in Mandalay, Myanmar.

Meanwhile, past researchers in Myanmar, such as Phyu and Cho (2016) and Aung (2018), have performed preliminary evaluations using the priority index (PI) method defined by Hassan and Sozen (1997). In the PI method, only the cross-sectional area of the column, reinforced concrete wall at base level, masonry walls filling frame bays, and summation of the floor area are used. The strength of the structural material and seismic vulnerability characteristics are not considered. Therefore, the PI method was not considered for the present study. Instead of the PI method, an Indian preliminary evaluation, which considered the facts that are not present in the PI method, was used.

In Linn and Tajiri (2014), the authors used the Japanese standard for design evaluation. Similarly, in Bangladesh, Rasel et al. (2015) and Halder et al. (2015) carried out a 
seismic evaluation with the Bangladesh method derived from the Japan Standard. As stated above, the Bangladesh method is more favorable than the Japanese method for the seismic assessment of buildings in Myanmar because Japan is a well-developed country and building technology is too different from Myanmar. Therefore, the Bangladesh method was chosen for the present study. And hence, RVS and preliminary evaluation are carried out for 26 numbers of low-rise buildings in the Mandalay region using FEMA P154 (USA method), the India standard, and the Bangladesh method. These are executed to investigate the condition of the existing buildings and to determine which buildings need detailed seismic safety assessments and retrofitting. The buildings were selected based on their seismically vulnerable characteristics, such as vertical irregularities, plan irregularities, soil condition, etc.

\section{MATERIALS AND METHODS}

\subsection{Rapid visual screening}

Rapid visual screening was carried out and each method followed an individual scoring system depending on the need and objectives. The scoring systems for the proposed method can be seen in Figure 1.

The results from these three RVS methodologies are scaled from one to five. They can be calculated from Equation 1 (Harirchian et al. 2020).

$$
X_{s}=\frac{X-X_{\min }}{X_{\max }-X_{\min }} \times(5-1)+1
$$

where $X_{S}$ is the scaled value of the obtained result, $X_{\min }$ is the lowest score, and $X_{\max }$ is the highest score.

\subsubsection{FEMA P-154 (USA method)}

In FEMA P-154, the basic score is defined on building type, the structural framing. The FEMA P-154 data collection form differs with the level of seismicity. The score modifiers used in level 1 are severe vertical irregularity VL1, moderate vertical irregularity VL1, plan irregularity, PL1, precode, post-benchmark and soil type. This level 1 form requires building information such as latitude, longitude, occupancy, and exterior falling hazards.

In level 2, detailed structural multipliers are included for vertical irregularity, plan irregularity, redundancy, pounding, building type, and retrofit. If the score is less than the minimum score, the screener can know this building will suffer $100 \%$ damage during an earthquake. If the score is less than the basic score, a detailed seismic evaluation is needed for this building (FEMA 2015).

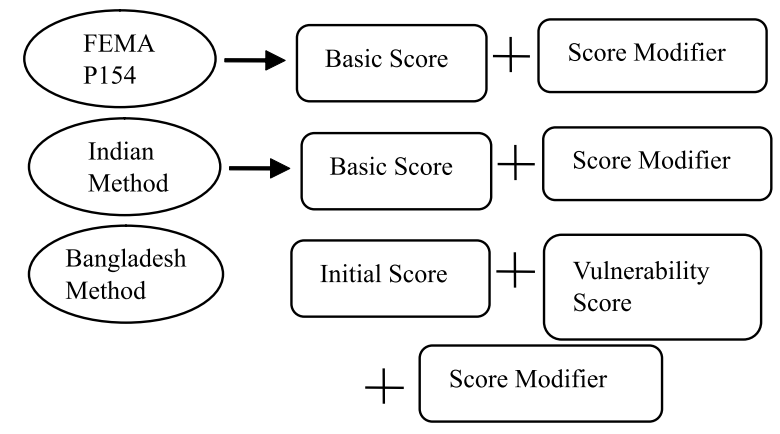

FIGURE 1. Proposed rapid visual screening methods.

\subsubsection{Indian method}

The RVS score evaluation using the Indian method is based on the number of stories, vertical irregularity, plan irregularity, code detailing, soil type, and liquefaction. The seismic zone is classified as per IS 1893:2002 (Part 1), depending on the earthquake magnitude MSK. The damage classifications are based on the European Macroseismic Scale (EMS98), which delineates building damage according to Grades 1 to 5 (Sinha and Goyal 2004). Since Mandalay has an equivalent modified Mercalli Scale class IX, filling the form of the Rapid Visual Screening of Building for Potential Seismic Vulnerability (Seismic Zone IV\&V) can be used for the seismic safety assessment of buildings in Mandalay.

\subsubsection{Bangladesh method}

The basic score in the Bangladesh method is determined from the number of stories and seismic hazard zone based on the peak ground velocity (PGV) (Equation 2). Soft story, heavy overhang, apparent quality, pounding effects, short columns, buildings on slope, plan irregularities, liquefaction vulnerability, and landslide vulnerability are taken into account by the vulnerability score and score multiplier. This method has a risk status that is concerned with the corresponding interval of the performance score (Amit et al. 2017). Mandalay has a higher PGV than that of the highest seismic hazard zone in Bangladesh. Thus, its buildings are more vulnerable than those of Bangladesh.

$$
P S=B S-\Sigma(V S M \times V S)
$$

where PS is the performance score, BS is the basic score, $V S M$ is the vulnerability score multiplier, and VS is the vulnerability score.

\subsection{Preliminary vulnerability assessment}

This assessment comprises a collection of drawings, onsite drawings, redrawing in AutoCAD, load calculation, and preliminary evaluation. Structural configuration and strength-related checks using NDT methods are also needed for this evaluation (Taru 2014). The Indian and Bangladesh methods were used for the preliminary assessment, which are for mid- to low-rise buildings with six stories or fewer. A detailed seismic evaluation must be carried out for buildings with more than six stories, such as the eight-story building no. 26 , which was thus excluded.

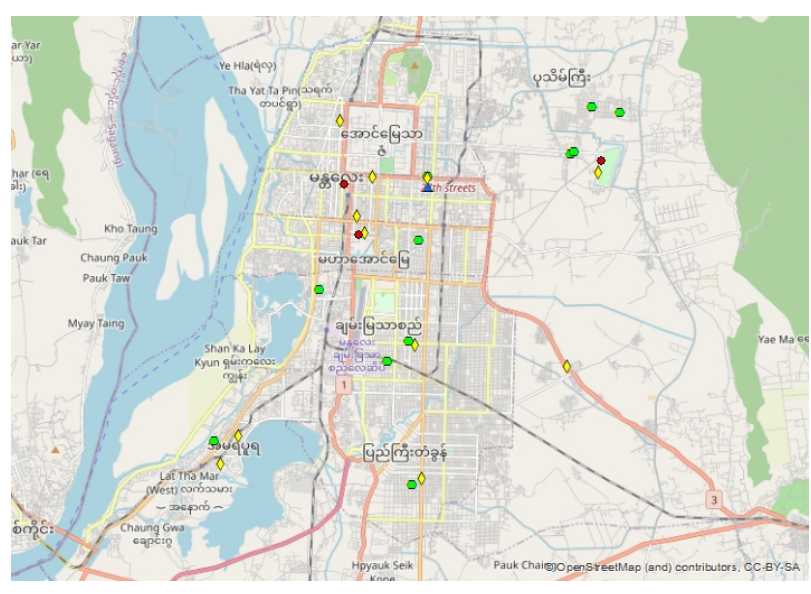

FIGURE 2. Building locations for case study. 
TABLE 1. Survey data for seismic safety assessment.

\begin{tabular}{|c|c|c|c|c|}
\hline Building no. & Township & No. of stories & Latitude & Longitude \\
\hline 1 & AMTZ 1 & 3 & N21.9825 & E96.1117 \\
\hline 2 & AMTZ 2 & 4 & N21.9819 & E96.1116 \\
\hline 3 & AMTZ 3 & 4 & N21.9990 & E96.0838 \\
\hline 4 & CATZ 1 & 4 & N21.9708 & E96.0892 \\
\hline 5 & CATZ 2 & 4 & N21.9823 & E96.0942 \\
\hline 6 & CATZ 3 & 5 & N21.9800 & E96.0847 \\
\hline 7 & MHAM 1 & 3 & N21.9634 & E96.1088 \\
\hline 8 & MHAM 2 & 4 & N21.9658 & E96.0917 \\
\hline 9 & MHAM 3 & 5 & N21.9650 & E96.0894 \\
\hline 10 & CMTZ 1 & 3 & N21.9339 & E96.1056 \\
\hline 11 & CMTZ 2 & 3 & N21.9490 & E96.0769 \\
\hline 12 & CMTZ 3 & 4 & N21.9329 & E96.1075 \\
\hline 13 & PGTG 1 & 3 & N21.9278 & E96.0987 \\
\hline 14 & PGTG 2 & 3 & N21.8914 & E96.1065 \\
\hline 15 & PGTG 3 & 4 & N21.8935 & E96.1097 \\
\hline 16 & AMRPR 1 & 3 & N21.9042 & E96.0434 \\
\hline 17 & AMRPR 2 & 4 & N21.9058 & E96.0512 \\
\hline 18 & AMRPR 3 & 4 & N21.8976 & E96.0455 \\
\hline 19 & PTG 1 & 3 & N22.0028 & E96.1640 \\
\hline 20 & PTG 2 & 3 & N21.9891 & E96.1570 \\
\hline 21 & PTG 3 & 3 & N22.0011 & E96.1729 \\
\hline 22 & PTG 4 & 3 & N21.9895 & E96.1583 \\
\hline 23 & PTG 5 & 4 & N21.9836 & E96.1659 \\
\hline 24 & PTG 6 & 4 & N21.9263 & E96.1562 \\
\hline 25 & PTG 7 & 5 & N21.9870 & E96.1668 \\
\hline 26 & CATZ 4 & 8 & N21.9790 & E96.1114 \\
\hline
\end{tabular}

Note: AMTZ = Aung Myay Thar Zan Township, CATZ = Chan Aye Thar Zan Township, MHAM = Mahar Aung Myay Township, CMTZ = Cha Mya Thar Z Township, PGTG = Pyi Gyi Tagon Township, AMRPR = Amarapura Township, PTG = Pathein Gyi Township.

\subsubsection{Indian method}

The preliminary vulnerability assessment using the Indian method needs to check the following stresses (Rai 2005): (i) shear stress in RC frame columns, which can be calculated using Equation 3, and (ii) axial stress in moment frames, which can be calculated using Equation 4.

$$
\tau_{c o l}=\left(\frac{n_{c}}{n_{c}-n_{f}}\right) \times\left(\frac{V_{j}}{A_{c}}\right)<0.4 \text { Mpa or } 0.1 \sqrt{f}_{c k}
$$

where $n_{c}$ is the total number of columns, $n_{f}$ is the total number of frames in the direction of loading, $A_{c}$ is the

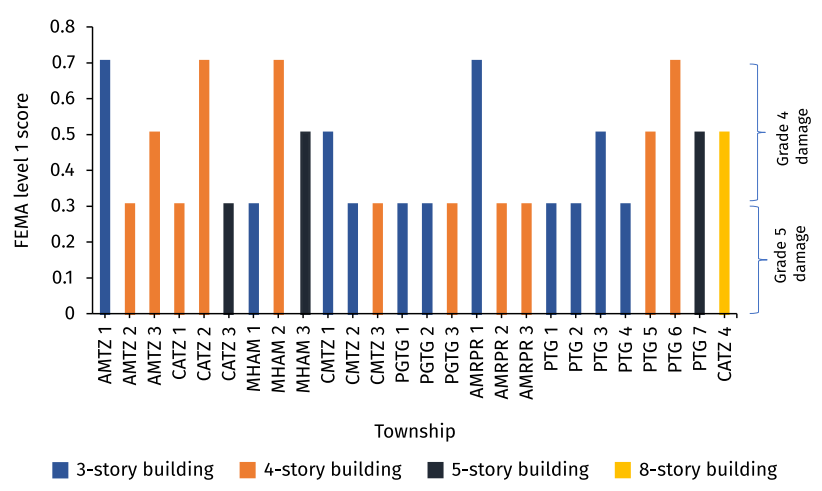

FIGURE 3. RVS results for all buildings based on FEMA P-154 Level 1. total cross-sectional area of columns, and $f_{c k}$ is the cube strength of concrete.

$$
F_{0}=\frac{2}{3} \times \frac{V_{B}}{n_{f}} \times \frac{H}{L}
$$

where $n_{f}$ is the total number of frames in the direction of loading, $V_{B}$ is the base shear, $H$ is the total height, and $L$ is the length of the building.

\subsubsection{Bangladesh method}

In the Bangladesh method, the seismic index of the structure and seismic demand index are calculated, and an evaluation is also carried out. These can be calculated using Equations 5 to 10 (Public Work Department 2015).

$$
I_{S} \geq I_{S O}
$$

where $I_{S}$ is the seismic index of the structure, and $I_{s o}$ is the seismic demand index of the structure.

$$
I_{S}=E_{0} \times S_{D} \times T
$$

where $E_{0}$ is the basic structural seismic capacity index (equal to $C$ [Strength Index $] \times F[$ Ductility Index $], S_{D}$ is a factor to modify the $E_{0}$-Index due to structural irregularity (torsion, soft story mechanism, etc.), and $T$ is a factor to allow for the deterioration of the original performance.

For the second level screening procedure, the calculations are as follows.

$$
E_{0}=\frac{n+1}{n+i} \sqrt{\left(E_{1}^{2}+E_{2}^{2}+E_{3}^{2}\right)}
$$

where $E_{1}=C_{1} \times F_{1} ; E_{2}=C_{2} \times F_{2} ; E_{3}=C_{3} \times F_{3} ; C_{1}, C_{2}$, and $C_{3}$ are the strength indices; and $F_{1}, F_{2}$, and $F_{3}$ are the ductility indices.

$$
E_{0}=\frac{n+1}{n+i} \times\left(C_{1}+\Sigma_{j}\left(\alpha_{j} \times C_{j}\right)\right) \times F_{1}
$$

where $a_{j}$ is the effective strength factor, $C=Q_{u} /(\Sigma W), Q_{u}$ is the ultimate lateral load carrying capacity of the vertical members in the story concerned, $\Sigma W$ is the weight of the building including live load for seismic calculation supported by the story concerned, and $E_{0}$ is taken as the lesser of the two values.

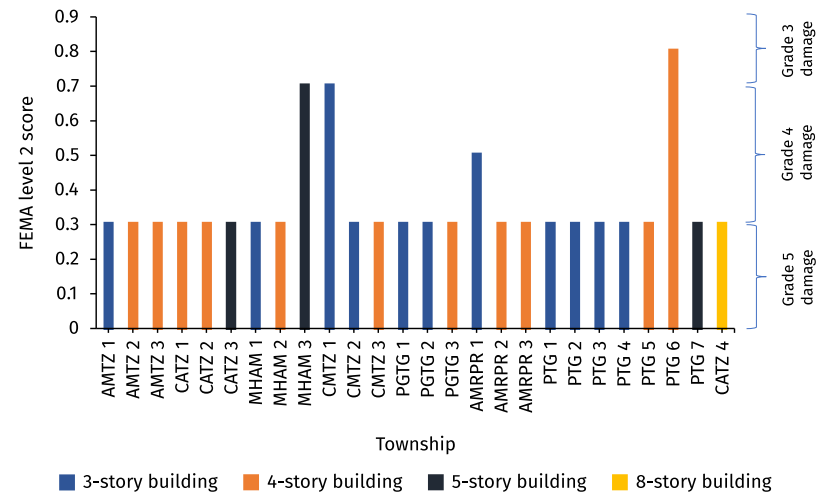

FIGURE 4. RVS results for all buildings based on FEMA P-154 Level 2. 


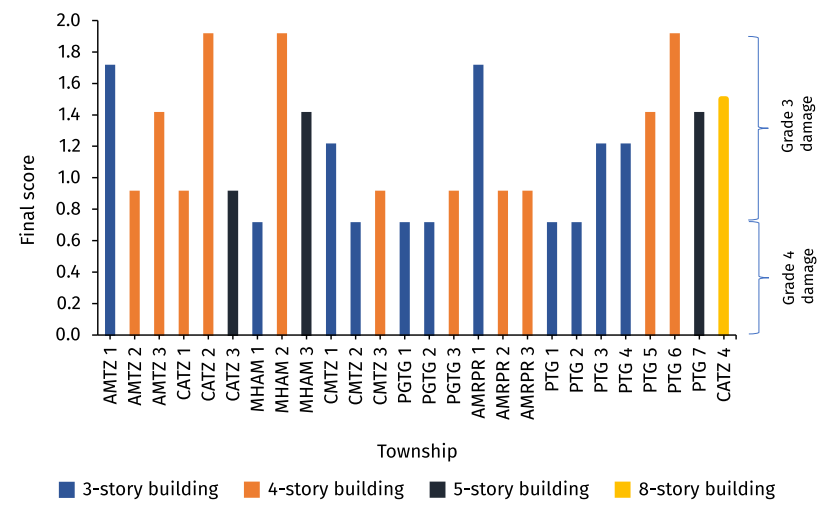

FIGURE 5. RVS results for all buildings based on Indian method.

$$
I_{s 0}=0.8 \times \frac{2}{3 Z} \times I \times C_{s}
$$

where $Z$ is the seismic zone coefficient (seismicity, expected PGA, etc.), $I$ is the structure importance factor, and $C_{S}$ is the normalized acceleration response spectrum. Moreover, this will satisfy the following equation.

$$
C_{T U} \times S_{D} \geq 0.4 \times \frac{2}{3} \times Z I C_{S}
$$

where $C_{T U}$ is the cumulative strength index at the ultimate deformation of the structure, $S_{D}$ is the irregularity index.

\subsection{Data survey and collection}

The seven major townships in Mandalay were selected for the collection and surveying of data, namely Aung Myay Thar Zan, Chan Aye Thar Zan, Mahar Aung Myay, Chan Mya Thar Zi, Pyi Gyi Tagon, Amarapura, and Patheingyi. The respective buildings' locations are shown in Figure 2, and the survey data can be seen in Table 1 .

\subsection{Seismic safety assessment using rapid visual screening methods}

A street survey was carried out for all 26 buildings using the three rapid visual screening methods. The Indian method is based on FEMA P-154 and the score filling systems are nearly the same, whereas the Bangladesh method differs.

\subsection{Seismic safety assessment using preliminary evaluation methods}

The preliminary evaluation is a quick procedure to establish the actual structural layout and assess its characteristics that can affect its seismic vulnerability. In the present

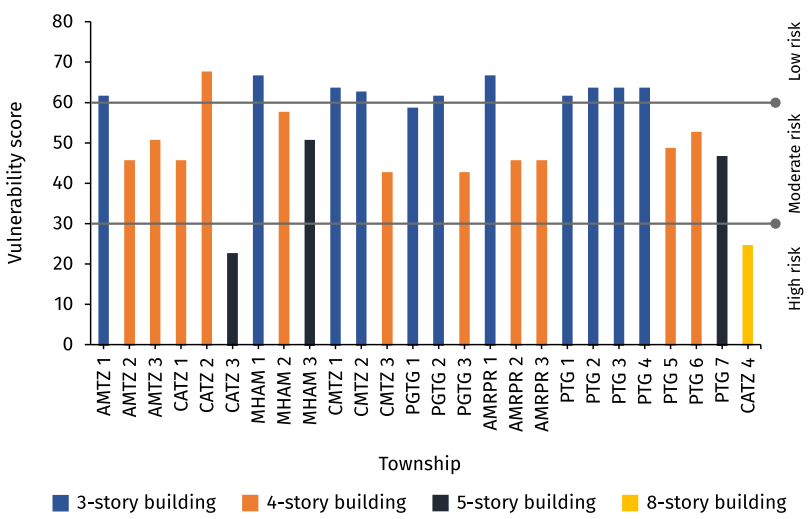

FIGURE 6. RVS results for all buildings based on Bangladesh method.

study, preliminary evaluation using the Indian method and seismic evaluation using the seismic index method with the Bangladesh method were implemented. These methods are from mid- to low-rise buildings with six stories or fewer. In contrast, a detailed seismic evaluation must be carried out for buildings that have more than six stories. As such, a total of 25 (three- to five-storied) buildings were assessed using the aforementioned methods.

\subsubsection{Preliminary evaluation using Indian method}

Building no. 2 was selected as the example of the preliminary evaluation using the Indian method. The shear stress in $\mathrm{X}$ and $\mathrm{Y}$ directions can be seen in Table 2 while the axial stress can be checked using equations $11-18$, specifically the axial stress in moment frames in the $\mathrm{X}$ and $\mathrm{Y}$ directions for building no. 2 (Equations 11 and 15, respectively) and their corresponding axial stresses (Equations 12, 13, 14 and Equations 16, 17, 18, respectively).

$$
\begin{aligned}
F_{0} & =\frac{2}{3} \times \frac{V_{B}}{n_{f}} \times \frac{H}{L} \\
& =\frac{2}{3}\left(\frac{1.5 \times 637.594}{2}\right) \times \frac{54}{52} \\
& =331.058 \mathrm{kN}
\end{aligned}
$$

\begin{tabular}{|c|c|c|c|c|c|c|c|c|c|c|c|c|c|c|c|}
\hline \multirow[t]{2}{*}{ Story } & \multicolumn{2}{|c|}{$n_{c}$} & \multicolumn{2}{|r|}{$n_{f}$} & \multicolumn{2}{|c|}{$A_{c}\left(m^{2}\right)$} & \multicolumn{2}{|c|}{$V_{j x} 1.5$} & \multicolumn{2}{|c|}{$\tau_{c o l}(M p a)$} & \multicolumn{2}{|c|}{$\tau_{\text {all }}$} & \multicolumn{2}{|c|}{$0.1\left(f_{c k}^{1 / 2}\right)$} & \multirow[t]{2}{*}{ Remark } \\
\hline & $x$ & $\mathrm{Y}$ & $\mathrm{X}$ & Y & $x$ & $\mathrm{Y}$ & $x$ & Y & $x$ & $\mathrm{Y}$ & $x$ & $\mathrm{Y}$ & $x$ & Y & \\
\hline SR & 4 & 4 & 2 & 2 & 0.37 & 0.37 & 11.27 & 11.27 & 0.06 & 0.06 & 0.4 & 0.4 & 0.42 & 0.42 & Satisfactory \\
\hline RF & 10 & 11 & 2 & 2 & 0.93 & 1.02 & 447.59 & 447.59 & 0.60 & 0.54 & 0.4 & 0.4 & 0.42 & 0.42 & Unsatisfactory \\
\hline $3 \mathrm{~F}$ & 10 & 11 & 2 & 2 & 0.93 & 1.02 & 763.34 & 763.34 & 1.03 & 0.91 & 0.4 & 0.4 & 0.42 & 0.42 & Unsatisfactory \\
\hline $2 \mathrm{~F}$ & 10 & 11 & 2 & 2 & 0.93 & 1.02 & 911.80 & 911.80 & 1.23 & 1.09 & 0.4 & 0.4 & 0.42 & 0.42 & Unsatisfactory \\
\hline $1 \mathrm{~F}$ & 10 & 11 & 2 & 2 & 0.93 & 1.02 & 955.36 & 955.36 & 1.29 & 1.14 & 0.4 & 0.4 & 0.42 & 0.42 & Unsatisfactory \\
\hline GF & 10 & 11 & 2 & 2 & 0.93 & 1.02 & 956.39 & 956.39 & 1.29 & 1.14 & 0.4 & 0.4 & 0.42 & 0.42 & Unsatisfactory \\
\hline
\end{tabular}

$$
\begin{aligned}
\tau & =\frac{331.058}{\frac{12 \times 12}{12^{2} \times 3.281^{2}}} \times 10^{-3} \\
& =3.564 \mathrm{Mpa}
\end{aligned}
$$

$$
\begin{aligned}
\tau_{\text {all }} & =0.25 \times f_{c k} \\
& =0.25 \times \frac{2500}{145} \\
& =4.31 \mathrm{Mpa}
\end{aligned}
$$

TABLE 2. Shear stress for building no. 2 in $X$ and $Y$ directions. 
$\tau<\tau_{\text {all }}$, satisfied

$$
\begin{aligned}
F_{0} & =\frac{2}{3} \times \frac{V_{B}}{n_{f}} \times \frac{H}{L} \\
& =\frac{2}{3} \times \frac{1.5 \times 637.594}{2} \times \frac{54}{60} \\
& =286.917 \mathrm{kN}
\end{aligned}
$$

$$
\begin{aligned}
\tau & =\frac{286.917}{\frac{12 \times 12}{12^{2} \times 3.281^{2}}} \times 10^{-3} \\
& =3.089 \mathrm{Mpa}
\end{aligned}
$$

$$
\begin{aligned}
\tau_{\text {all }} & =0.25 \times f_{\text {ck }} \\
& =0.25 \times \frac{2500}{145} \\
& =4.31 \mathrm{Mpa}
\end{aligned}
$$

$$
\tau<\tau_{\text {all }}, \text { satisfied }
$$

From these equations, the axial stress was satisfied, in both directions of building no. 2 .

\subsubsection{Seismic evaluation using seismic index method with Bangladesh method}

The seismic evaluation of building no. 2 was carried out following Table 3.

\section{RESULTS AND DISCUSSION}

\subsection{RVS}

\subsubsection{FEMA level 1 and level 2}

In RVS using FEMA P-154 level 1, all of the buildings required detailed seismic evaluations, because their seismic performance scores were lower than the basic score (Figure 3 ). Fourteen out of 26 buildings had the minimum score. Thus, over $50 \%$ of the buildings observed $(\mathrm{S}<0.3)$ may encounter a high probability of Grade 5 damage and the remaining buildings, which are $0.3<\mathrm{S}<0.7$, will have a high probability of Grade 4 damage.

The scores for all buildings were lower than the basic score and 22 out of 26 buildings had the minimum score, based on FEMA P-154 level 2 (Figure 4). According to the results, these 22 buildings will face a high probability of Grade 5 damage during an earthquake. A high probability of Grade 4 damage was accorded to three of the remaining buildings and only one building may have a high probability of Grade 3 damage during an earthquake.

In FEMA level 1 and level 2 screenings, all buildings required further detailed seismic evaluation. The three-story buildings in Aung Myay Thar Zan, Mahar Aung Myay, Pyi Gyi Tagon, and Patheingyi will have a probability of Grade 5 damage and they may collapse during a strong earthquake. Three-story buildings in Chan Mya Thar Zi and Amarapura, meanwhile, will encounter Grade 4 damage.

In four-story buildings, all of the buildings except for one in Patheingyi township will have a high probability of Grade 5 damage based on FEMA P-154 level 2 screening. Although some buildings have a high probability of Grade 4 damage in FEMA P-154 level 1, their scores dropped to the minimum score in FEMA P-154 level 2. Consequently, only one four-story building, in Patheingyi, may have a high probability of Grade 3 damage.

The five-story building in Chan Aye Thar Zan township may face a high probability of Damage 5 based on FEMA P-154 levels 1 and 2 RVS. The five-story building in Mahar Aung Myay may have a high probability of Grade 4 damage in both FEMA P-154 level 1 and level 2 screenings.

The eight-story building in Chan Aye Thar Zan township and five-story building in Patheingyi township were found to have a high probability of Grade 4 damage at level 1 screening, but they may possess Grade 5 damage based on level 2 screening.

Ramly et al. (2014) conducted a seismic vulnerability assessment of existing buildings in Bukit Tinggi, Pahang, Malaysia. They used the FEMA P-154 level 1 rapid visual screening method in moderate seismicity, and found that $26 \%$ of buildings needed further evaluation. In contrast, it can be seen that all of the buildings needed a detailed seismic evaluation in the present study, because Mandalay is in a high seismicity zone, and hence, the FEMA P-154 level 1 and level 2 rapid visual screening methods in high seismicity were used. Moreover, the buildings in this study were selected based on their seismic vulnerability parameters.

\subsubsection{Indian method}

Based on the Indian method results, only six in total threestory buildings were found to have a high probability of Grade 4 damage, and the remaining buildings have a high probability of Grade 3 damage. None of the buildings assessed have a high probability of Grade 5 damage. The In-

\begin{tabular}{|c|c|c|c|c|c|c|c|c|c|c|c|c|c|c|c|c|c|}
\hline \multirow[t]{2}{*}{ Story } & \multicolumn{2}{|c|}{$\Sigma W_{i} k N$} & \multicolumn{2}{|c|}{$(n+1) /(n+j)$} & \multicolumn{2}{|c|}{$\Sigma C$} & \multicolumn{2}{|c|}{$E_{0}$} & \multicolumn{2}{|c|}{$I_{S}$} & \multicolumn{2}{|c|}{$I_{S 0}$} & \multicolumn{2}{|c|}{$C_{T} U S_{D}$} & \multicolumn{2}{|c|}{$0.4 \times 2 / 3 Z I C_{s}$} & \multirow[t]{2}{*}{ Evaluation } \\
\hline & $\mathrm{X}$ & $\mathrm{Y}$ & $x$ & Y & $\mathrm{X}$ & Y & $x$ & $\mathrm{Y}$ & $X$ & $\mathrm{Y}$ & $x$ & $\mathrm{Y}$ & $x$ & $\mathrm{Y}$ & $x$ & $\mathrm{Y}$ & \\
\hline RF & 2029 & 2029 & 0.60 & 0.60 & 1.69 & 1.51 & 1.01 & 0.91 & 0.91 & 0.82 & 0.58 & 0.58 & 0.91 & 0.82 & 0.29 & 0.29 & Safe \\
\hline $3 F$ & 4955 & 4955 & 0.67 & 0.67 & 0.69 & 0.62 & 0.46 & 0.41 & 0.42 & 0.37 & 0.58 & 0.58 & 0.42 & 0.37 & 0.29 & 0.29 & Not safe \\
\hline $2 \mathrm{~F}$ & 7881 & 7881 & 0.75 & 0.75 & 0.43 & 0.39 & 0.33 & 0.29 & 0.29 & 0.26 & 0.58 & 0.58 & 0.29 & 0.26 & 0.29 & 0.29 & Not safe \\
\hline $1 \mathrm{~F}$ & 10807 & 10807 & 0.86 & 0.86 & 0.32 & 0.28 & 0.27 & 0.24 & 0.24 & 0.22 & 0.58 & 0.58 & 0.24 & 0.22 & 0.29 & 0.29 & Not safe \\
\hline GF & 13733 & 13733 & 1.00 & 1.00 & 0.18 & 0.18 & 0.18 & 0.18 & 0.16 & 0.17 & 0.58 & 0.58 & 0.16 & 0.17 & 0.29 & 0.29 & Not safe \\
\hline
\end{tabular}
dian method RVS results are shown in Figure 5.

Verma et al. (2017) conducted a seismic vulnerability assessment of buildings in Locknow by using the Indian method. Visuvasam et al. (2017) also carried out a seismic vulnerability assessment of existing residential buildings at Vellore using this method. Their results showed that RVS can be effectively used for seismic safety assessments.

TABLE 3. Seismic evaluation of building no. 2 in $X$ and $Y$ directions using seismic index method. 
TABLE 4. Ranges of scaled RVS results with damage state definition.

\begin{tabular}{lll}
\hline $\begin{array}{l}\text { Scaled } \\
\text { RVS } \\
\text { results }\end{array}$ & $\begin{array}{l}\text { Considered } \\
\text { integer for } \\
\text { damage state }\end{array}$ & Definition \\
\hline $1.00-1.55$ & 1 & $\begin{array}{l}\text { Very high probability of Grade } 5 \text { and } \\
\text { high probability of Grade } 4 .\end{array}$ \\
$1.56-2.55$ & 2 & $\begin{array}{l}\text { Moderate probability of Grade } 4 \text { and } \\
\text { high probability of Grade } 3 .\end{array}$ \\
$2.56-3.55$ & 3 & $\begin{array}{l}\text { Very high probability of Grade } 3 \text { and } \\
\text { little probability of Grade } 2 .\end{array}$ \\
$3.56-4.55$ & 4 & $\begin{array}{l}\text { Very high probability of Grade } 2 \text { and } \\
\text { little probability of Grade } 1 . \\
\text { Little probability of Grade } 2 \\
\text { and very high probability of Grade 1. }\end{array}$ \\
\hline
\end{tabular}

In the present study, a total of 26 buildings in Mandalay were assessed using the Indian RVS method in high seismicity. The basic score depends on the building type, while the score modifiers primarily depend on the vertical irregularity, plan irregularity, and soil type. The Mandalay regions has good soil properties and no liquifiable soil. Therefore, the vertical irregularity and plan irregularity are important with respect to this study.

Our results showed that a detailed evaluation for all buildings needs to be carried out because the buildings have vertical irregularity, plan irregularity, or both of these irregularities. The structural damage states are a little lower than FEMA Level 1 and Level 2 screenings.

\subsubsection{Bangladesh method}

In terms of the Bangladesh method, 10 out of 11 three-story buildings were low risk and only one three-story building was found to have a moderate risk (Figure 6). Similarly, only one four-story building is at low risk while the other fourstory buildings are at moderate risk. Of the five-story and eight-story buildings, two in Chan Aye Thar Zan Township are at high risk and the other two five-story buildings may suffer moderate damage in an earthquake.

A study by Amit et al. (2017) showed that the seismic risk level of a nine-storied building is higher than that of a six-storied building. The results in the present study were consistent with theirs. Here, the Bangladesh method also revealed that the buildings which may encounter moderate risk and high risk require a subsequent detailed seismic evaluation. According to the results, it was found that the base score mainly depends upon the number of stories and thus the higher the story, the higher the seismic risk status.

\subsubsection{Scaled damage based on all methods}

According to all of the aforementioned assessments, all buildings need further detailed seismic evaluations. RVS results can be scaled to have similar results from Equation 1 (Harirchian et al. 2020). For FEMA P-154 levels 1 and 2, and the Indian method, Xmin can be used as 0.3. Xmax is 2.5 for FEMA and 3 for the Indian method. In the Bangladesh method, Xmax is 80 for three- to eight-story buildings. Xmin is used as 20 because the minimum scaled value of the obtained result is 22 . The ranges of the scaled rapid visual screening results with damage state definitions followed those outlined in Table 4.

Taking the damage states of all buildings from the combined RVS results into account, all three-story buildings in Pathein Gyi township, and four-story buildings in Pyi Gyi
Tagon township and Amarapura may be highly vulnerable to seismic loads (Figure 7). It can be seen that the five- and 8-story buildings in Chan Aye Thar Zan township are the most vulnerable according to the seismic assessment results. Almost all buildings in Chan Mya Thar Zi township may undergo severe damage during an earthquake.

Harirchian et al. (2020) presented an overview of the common RVS methods, FEMA P-154, Indian method (IITKGGSDMA), and Turkish method (EMPI). They found that FEMA P-154 was the most prone to overestimation during damage evaluations and Indian RVS was more significant than the Turkish RVS method. Similarly, the present study found that FEMA P-154 level 1 and level 2 showed extremely an high possibility of damage. The Indian method showed more damage situations than the Bangladesh method. The preliminary evaluation was implemented to get more specific data for the seismic safety assessment.

\subsection{Preliminary vulnerability assessment}

The preliminary evaluation results using the Indian and Bangladesh methods are shown in Tables 5 and 6. In the Indian standard, one significant factor in these calculations is the assessment result of building no. 6 . This building has the required strength, but the structural irregularity and other important factors were not considered in the calculation. The Bangladesh method requires more detailed parameters in the calculation and thus it can result in a more accurate data and vulnerability assessment.

Hashmi (2015) analyzed the shear stress generated in the column section, the axial force, and the axial stress generated in the column at base level by varying the control parameters. He concluded that the building is marginally safe against shear strength demand, and very safe against axial compression under seismic loading. From his study, it can be known that the concrete strength mainly controls the shear stress, and that concrete strength and ratio of height to length of the buildings are important for overturning force and axial stress.

In the present study, most of the buildings were found to be safe against axial stresses and not safe against shear stresses. It can be considered that the buildings may not have the required concrete strength, and number and areas of the columns. After further research, the specified concrete strength and area of the column can be defined for the buildings in high seismic regions.

In Bangladesh, Rasel et al. (2015) proposed the retrofitting process of existing buildings to resist seismic

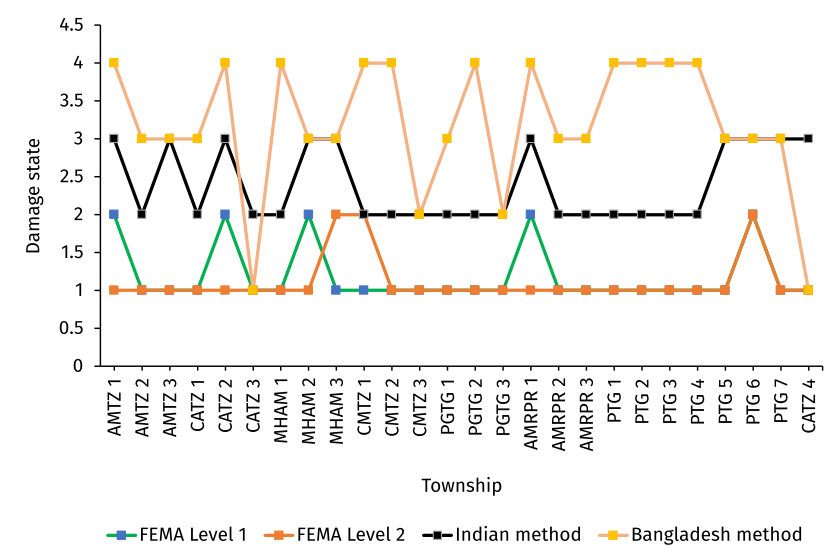

FIGURE 7. Damage state for all building data from RVS methodologies. 
TABLE 5. Preliminary evaluation results based on Indian method.

\begin{tabular}{|c|c|c|c|c|c|}
\hline \multirow[t]{2}{*}{$\begin{array}{l}\text { Building } \\
\text { no. }\end{array}$} & \multicolumn{2}{|c|}{$\begin{array}{l}\text { Shear stress } \\
\text { direction }\end{array}$} & \multicolumn{2}{|c|}{$\begin{array}{l}\text { Axial stress } \\
\text { direction }\end{array}$} & \multirow[t]{2}{*}{$\begin{array}{l}\text { Detailed seismic } \\
\text { evaluation is required }\end{array}$} \\
\hline & $x$ & $Y$ & $x$ & $Y$ & \\
\hline 1 & NS & $S$ & $S$ & $S$ & Yes \\
\hline 2 & NS & NS & $S$ & $S$ & Yes \\
\hline 3 & NS & $S$ & $S$ & $S$ & Yes \\
\hline 4 & NS & $S$ & $S$ & $\mathrm{~S}$ & Yes \\
\hline 5 & NS & NS & $S$ & $S$ & Yes \\
\hline 6 & $S$ & $S$ & $S$ & $S$ & No \\
\hline 7 & NS & NS & $\mathrm{S}$ & $\mathrm{S}$ & Yes \\
\hline 8 & NS & $S$ & $S$ & $S$ & Yes \\
\hline 9 & NS & NS & $S$ & $S$ & Yes \\
\hline 10 & NS & NS & $\mathrm{S}$ & $\mathrm{S}$ & Yes \\
\hline 11 & $S$ & NS & $S$ & $S$ & Yes \\
\hline 12 & NS & NS & $S$ & $S$ & Yes \\
\hline 13 & NS & NS & $\mathrm{S}$ & $\mathrm{S}$ & Yes \\
\hline 14 & NS & NS & $S$ & $S$ & Yes \\
\hline 15 & NS & NS & $S$ & $S$ & Yes \\
\hline 16 & NS & NS & $S$ & $S$ & Yes \\
\hline 17 & NS & NS & $\mathrm{S}$ & $\mathrm{S}$ & Yes \\
\hline 18 & NS & NS & $S$ & $S$ & Yes \\
\hline 19 & NS & NS & $S$ & NS & Yes \\
\hline 20 & NS & NS & NS & $S$ & Yes \\
\hline 21 & NS & $S$ & $\mathrm{~S}$ & $\mathrm{~S}$ & Yes \\
\hline 22 & NS & NS & NS & $S$ & Yes \\
\hline 23 & NS & NS & $S$ & $S$ & Yes \\
\hline 24 & NS & NS & NS & NS & Yes \\
\hline 25 & NS & NS & $\mathrm{S}$ & $S$ & Yes \\
\hline
\end{tabular}

Note: NS = not satisfied, $\mathrm{S}=$ satisfied.

loads. They calculated the demand capacity ratio and carried out retrofitting of beams by steel plating and interior columns by concrete jacketing. All of the buildings assessed in the present study require detailed seismic evaluations, because their seismic indices are less than the seismic demands of the respective structures. These buildings should be retrofitted to have the required seismic demand. From the results of the preliminary evaluation based on the Indian standard and Bangladesh method, not only are detailed seismic evaluations necessary for these buildings, but retrofitting strategies must be carried out for some of them, as well.

\section{CONCLUSIONS}

In this study, rapid visual screening methods comprising FEMA P-154 level 1, FEMA P-154 level 2, the Indian method, and the Bangladesh methods were used to assess the seismic safety of 26 existing three- to eight-story RC buildings in Mandalay, Myanmar. The results of each method can be concluded as follows.

1. FEMA P-154 level 1 and level 2 showed the highest risk. This method is not recommended because it is an overestimation.

2. The Indian method is a moderate way for both rapid visual screening and preliminary evaluation. It is recommended for low-rise buildings and is an efficient way for RVS methodology.
TABLE 6. Preliminary evaluation results based on Bangladesh method.

\begin{tabular}{|c|c|c|c|}
\hline \multirow[t]{2}{*}{$\begin{array}{l}\text { Building } \\
\text { no. }\end{array}$} & \multicolumn{2}{|c|}{$\begin{array}{l}\text { Seismic evaluation } \\
\text { direction }\end{array}$} & \multirow[t]{2}{*}{$\begin{array}{l}\text { Detailed seismic } \\
\text { evaluation is required }\end{array}$} \\
\hline & $x$ & Y & \\
\hline 1 & NS & $S$ & Yes \\
\hline 2 & NS & NS & Yes \\
\hline 3 & NS & NS & Yes \\
\hline 4 & NS & NS & Yes \\
\hline 5 & NS & $S$ & Yes \\
\hline 6 & NS & NS & Yes \\
\hline 7 & NS & NS & Yes \\
\hline 8 & NS & $S$ & Yes \\
\hline 9 & NS & NS & Yes \\
\hline 10 & NS & NS & Yes \\
\hline 11 & NS & NS & Yes \\
\hline 12 & NS & NS & Yes \\
\hline 13 & NS & NS & Yes \\
\hline 14 & NS & NS & Yes \\
\hline 15 & NS & NS & Yes \\
\hline 16 & NS & NS & Yes \\
\hline 17 & NS & NS & Yes \\
\hline 18 & NS & NS & Yes \\
\hline 19 & NS & NS & Yes \\
\hline 20 & NS & NS & Yes \\
\hline 21 & NS & NS & Yes \\
\hline 22 & NS & NS & Yes \\
\hline 23 & NS & NS & Yes \\
\hline 24 & NS & NS & Yes \\
\hline 25 & NS & NS & Yes \\
\hline
\end{tabular}

Note: $\mathrm{NS}=$ not satisfied, $\mathrm{S}=$ satisfied

3. The results of the Bangladesh method depend mainly on the number of stories and so it is more suitable for the assessment of high-rise buildings.

4. The preliminary evaluation using the Bangladesh method can result in more detailed seismic vulnerability results than the Indian method. However, in the Bangladesh method, the seismic index and seismic demand index calculations take more factors into account and more effort and technical skill are needed to obtain accurate data.

Seismic vulnerability assessments with different methods can save time, funds, and energy. RVS and preliminary evaluations should be carried out for all existing buildings and new buildings located in high seismic regions. Some seismic design control parameters such as column size, steel percentage, and material strength can be determined from the seismic safety assessment of existing buildings and these design parameters should be standardized for new buildings. Finally, further research can employ standard RVS methods and preliminary evaluations can be derived for the buildings in Myanmar and those in other ASEAN countries with similar seismic zones.

\section{ACKNOWLEDGMENTS}

The authors would like to acknowledge Dr. Nilar Aye, Professor and Head, Department of Civil Engineering, Mandalay Technological University for her kind permission and 
suggestions throughout the preparation of this paper. The first author also wishes to express her deepest gratitude to her beloved family for providing mental support and needs.

\section{AUTHORS' CONTRIBUTIONS}

MMMA designed the study. MMMA carried out the data survey. MMMA analyzed the data. MMMA and MNA wrote the manuscript. All authors read and approved the final version of the manuscript.

\section{COMPETING INTERESTS}

The authors have no competing interests to declare.

\section{REFERENCES}

Amit SK, Islam M, Alam M. 2017. A methodology for seismic vulnerability assessment of existing RC buildings. Paper presented at: ICDRM 2017. Proceedings of the International Conference on Disaster Risk Mitigation; Dhaka, Bangladesh.

Aung NN. 2018. Seismic vulnerability distribution map for low-rise RC buildings in Chan Aye Thar San township. Paper presented at: NCSE 2018. Proceedings of the Eleventh National Conference on Science and Engineering; Patheingyi, Myanmar.

Aye TRM, Aye MN. 2019. Seismic evaluation of existing buildings in selected areas of Lanmadaw township [bachelor thesis]. [Yangon]: West Yangon Technological University.

[FEMA] Federal Emergency Management Agency. 2015. Rapid visual screening of buildings for potential seismic hazards: a handbook. 3rd edition. Washington, DC: Federal Emergency Management Agency.

Halder AK, Inoue A, Nakajima Y, Islam MR. 2015. Seismic retrofitting of a garments factory building in Bangladesh. Paper presented at: USMCA 2015. Proceedings of the 14th International Symposium on New Technologies for Urban Safety of Mega Cities in Asia; Kathmandu, Nepal.

Harirchian E, Lahmer T, Buddhiraju S, Mohammad K, Mosavi A. 2020. Earthquake safety assessment of buildings through rapid visual screening. Buildings. 10(3):51. doi:10.3390/buildings10030051.

Hashmi A. 2015. Preliminary seismic evaluation aid for reinforced concrete structures based on IS 15988 (2013) guidelines. Indian Concr J. 89:12-16.

Hassan AF, Sozen MA. 1997. Seismic vulnerability assessment of low-rise buildings in regions with infrequent earthquakes. ACI Struct J. 94(1):31-39. doi:10.14359/4 58.

Linn WP, Tajiri S. 2014. Modified seismic evaluation method for reinforced concrete buildings in Myanmar. Bull Int Inst Seismol Earthquake Eng. 48:73-78.

Phyu EP, Cho AM. 2016. Seismic vulnerability distribution map for low-rise RC buildings in Mahar Aung Myay township. Paper presented at: NCSE 2016. Proceedings of the Ninth National Conference on Science and Engineering; Patheingyi, Myanmar.

Public Work Department. 2015. Manual for seismic retrofit design of existing reinforced concrete buildings. Dhaka: Public Work Department.

Rai DC. 2005. IITK-GSDMA guidelines for seismic evaluation and strengthening of existing buildings. Kanpur: Indian Institute of Technology Kanpur.

Ramly N, Ghafar M, Alel MNA, Adnan A. 2014. Rapid visual screening method for seismic vulnerability assessment of existing buildings in Bukit Tinggi, Pahang, Malaysia. Paper presented at: ACSM 2014. Proceedings of the International Conference on Advances in Civil, Structural and Mechanical Engineering; Birmingham, United Kingdom.

Rasel MM, Rahman MA, Ali AB, Islam MM, Rahman MM. 2015. Retrofitting process of an existing building with respect to seismic consideration in Bangladesh. Int J Sci Eng Res. 6(5):1051-1056. https://www.ijser.org/on lineResearchPaperViewer.aspx?Retrofitting-Processof-an-Existing-Building-With-Respect-To-SeismicConsideration-in-Bangladesh.pdf.

Sinha R, Goyal A. 2004. A national policy for seismic vulnerability assessment of buildings and procedure for rapid visual screening of buildings for potential seismic vulnerability. Bombay: Department of Civil Engineering, Indian Institute of Technology Bombay.

Taru. 2014. Integrated rapid visual screening of buildings for seismic hazard. Gurgaon: Taru Leading Edge.

UN-Habitat. 2016. Myanmar national building code (MNBC). Yangon: UN-Habitat. https://www.mes.org.mm/con tent/myanmar-national-building-code.

Verma U, Bhatt A, Ahmad R, Mishra P. 2017. Seismic vulnerability assessment of buildings in Lucknow. Int J Eng Res Technol. 6(6):45-49. doi:10.17577/ijertv6is060005.

Visuvasam J, Simon J, Chandrasekar R. 2017. Seismic vulnerability assessment of existing residential building at Vellore. Int J Civ Eng Technol. 8(4):604-610.

Win AHE, Zaw ASH. 2018. Seismic vulnerability assessment of existing buildings in downtown Yangon, Myanmar. Proceedings of the 7th International Conference on Modern Research in Civil Engineering, Architectural \& Urban Development. Munich, Germany. p. 147-157. doi:10.33422/7cau.2018.10.70.

Yakut A. 2014. Examination of seismic performance assessment procedures for RC buildings in Turkey. doi: 10.4231/D3B27PR8K. 